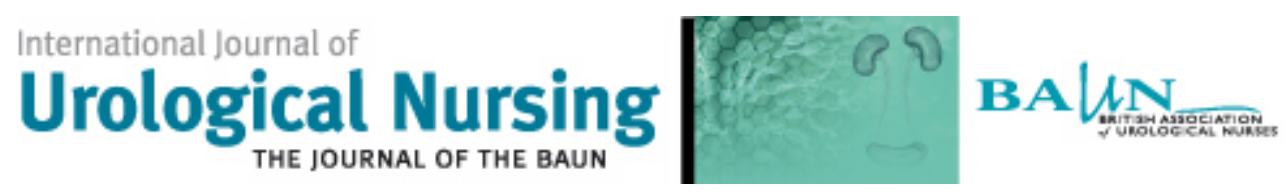

\title{
PATTERNS OF PATIENT WITHDRAWAL FROM BCG TREATMENT FOR BLADDER CANCER: A RETROSPECTIVE TIME INTERVAL ANALYSIS
}

\begin{tabular}{|r|l|}
\hline Journal: & International Journal of Urological Nursing \\
\hline Manuscript ID & IJUN-2019-0374.R1 \\
\hline Manuscript Type: & Original Research Article \\
\hline Keywords: & $\begin{array}{l}\text { Bladder Cancer, Non-muscle invasive bladder cancer, Urothelial cancer, } \\
\text { Bacillus Calmette-Guerin, BCG, Intravesical treatment, Early withdrawal }\end{array}$ \\
\hline
\end{tabular}

\section{SCHOLARONE $^{\text {Th }}$ \\ Manuscripts}




\title{
PATTERNS OF PATIENT WITHDRAWAL FROM BCG TREATMENT FOR BLADDER CANCER: A RETROSPECTIVE TIME INTERVAL ANALYSIS
}

\begin{abstract}
Research Aims

What were the patterns that have been recorded for withdrawal from treatment?

What individual factors influenced withdrawal from BCG treatment?

\section{Literature Review}

Bacillus Calmette-Guerin (BCG) vaccine was first introduced at the turn of the 19-20th century and since the 1970s has become significant in the treatment of non-muscle invasive bladder cancer (NMIBC). It is concerning to note that little is known about the patient experience of this intravesical treatment, which is particularly concerning. Despite over 50 years of clinical use, early withdrawal from treatment rates of between $32 \%-86 \%$ have been reported in the literature. This study sought to estimate the rate of non-completion of BCG regime in one English National Health Service Cancer Unit and identify factors that contributed to patients' decisions to withdraw.

\section{Methodology}

A retrospective observational time interval study of a consecutive sample 234 case records of patients who underwent intravesical BCG treatment in one English National Health Service Cancer Unit, using time to event analysis. The population for this review was from a large metropolitan area in England, including a large northern town and satellites where heavy industry had dominated.

\section{Results}

The overall withdrawal rate was $211(90 \%)$ prior to completion of induction and maintenance regime. The majority, 107 (46\%) withdrew-from treatment within the first 
year. Age, number of side effects and symptoms, and contact with CNS were all associated with withdrawal.

\section{Conclusions}

The data has shown that age, side effects, contact details and information giving may be factors that contribute to a patient deciding whether they stay on treatment or withdraw from it.

\section{Funding / Competing interests}

None to declare

\section{Keywords}

Bladder cancer, Non-muscle invasive bladder cancer, Urothelial cancer, Bacillus Calmette-Guerin, BCG, Intravesical treatment, Early withdrawal 


\section{Introduction}

In 2015 , there were over 10,000 new cases of bladder cancer recorded in the UK only

1. This accounts for $3 \%$ of all new cancer cases, with males being three times more likely to develop the disease than females. It is highest in people aged 85-89 years. The incidence rates for bladder cancer have been seen to be falling since the early 1990's. Reasons offered for this decline include reductions in tobacco smoking or exposure to occupational carcinogens, particularly amongst men ${ }^{2}$. There has also been a shift from industrial to predominantly service occupations in the UK ${ }^{3}$. Although tobacco smoking is still associated with around $50 \%$ of bladder cancers ${ }^{4-7}$ and more prevalent amongst people living in deprived areas ${ }^{1}$.

Transitional cell bladder cancer or urothelial cancer accounts for approximately $90 \%$ of all bladder cancers in the UK ${ }^{1}$. Non-muscle invasive, superficial or early, bladder cancer is characterised by abnormal cells localised to the lining of the bladder. Apart from recommended lifestyle changes such as smoking cessation, following a transurethral resection of bladder tumour (TURBT) intravesical treatment with Bacillus Calmette-Guerin (BCG) is considered the gold standard for preventing recurrence and disease progression in non-muscle invasive bladder cancer (NMIBC) ${ }^{8}$. Intravesical treatment involves instilling BCG into the bladder via a catheter. A proportion of patients, in some studies as high as $86 \%$, fail to complete treatment ${ }^{9}$. This low level of concordance could have consequences in terms of disease progression and ultimately need for radical surgical interventions.

At the turn of the $19-20^{\text {th }}$ century Albert Calmette and Camille Guerin isolated an attenuated live strain of Mycobacterium bovis bacillus, a live vaccine against 
tuberculosis, known as BCG ${ }^{10,11}$. During a series of post mortems in 1929, Pearl noted a lower incidence of bladder cancer in patients with tuberculosis ${ }^{12}$. Subsequent laboratory studies demonstrated the anti-tumour effects of BCG against several malignant cell lines ${ }^{13-16}$. In the late seventies Morales et al. (1976) undertook a preliminary study evaluating the effects of BCG treatment on nine patients with NMIBC. Study participants were treated with intravesical BCG once a week for sixweeks, achieving a complete response rate in $7(78 \%)$ of patients ${ }^{17}$. The effectiveness of this regime was later replicated in both the American South Western Oncology Group (SWOG) and the Memorial Sloan-Kettering Hospital in larger well designed control trials ${ }^{18-21}$.

Several well designed randomised clinical trials have since compared TURBT as a single treatment, against a TURBT followed by BCG ${ }^{18,22-24}$. Other randomised trials and meta-analyses compared various combinations of TURBT, chemotherapy and BCG regimes ${ }^{9,25-30}$. These studies demonstrated significant reductions in NMIBC recurrence rates of up to $57 \%$ in patients treated with BCG, compared to rates of up to $32 \%$ when treated with TURBT alone, or with chemotherapy.

Globally sub strains of BCG such as Pasteur, TICE, Armand-Frappier, Glaxo, Connaught and others are in use ${ }^{31}$ creating an absence of clarity regarding optimum strain or dose, as well as different regimes and doses ${ }^{30-32}$. A consensus statement concluded that regimens other than SWOG have not shown the same reliability ${ }^{33}$. Only one study compared two strains head to head ${ }^{34}$. They compared the Connaught and TICE strains and showed a statistically significant difference $(p<0.002)$ in five-year recurrence-free survival for Connaught (75\%) over TICE (46\%) treated patients. 
At present there remains no overwhelming evidence indicating the optimal efficacy for the most appropriate induction and maintenance regime. This is illustrated in table 1. Induction BCG was first introduced by Morales et al. and is normally given using a sixweekly regime. Results from the SWOG 8507 trial $^{9}$ and European Organisation for Research and Treatment of Cancer (EORTC) 30911 trial ${ }^{27}$, recommend an induction regimen of weekly instillations for six weeks, followed by a maintenance schedule of weekly instillations for three weeks at months $3,6,12,18,24,30$, and 36 for a total of 27 instillations for three years. Maintenance for three years was affirmed by a subsequent EORTC trial ${ }^{35}$. This regimen has now been recommended by the American Urological Association (AUA) and the European Association of Urology (EAU) as well as in local guidelines ${ }^{36-39}$. The EAU guidance recommends that at least one year of maintenance treatment is required to gain superior outcomes over Mitomycin (MMC) treatment ${ }^{8}$. The absence of an established optimal induction and maintenance schedule may be as a consequence of the wide variations in regimes in current use ${ }^{40-42}$. Moreover, the original and subsequent trial design irrespective of minor variations have all adopted an induction and maintenance model yet report high levels of attrition. Clinical practice has adopted the same model.

This paper presents the results of a study investigating the clinical experiences of patients receiving BCG treatment, using retrospective time interval analysis from case notes. This was the first phase in a larger mixed methods study exploring the reasons why patients withdrew from BCG treatment early.

Insert Table 1 
From the literature the following question emerged which the time interval analysis sought to answer: what were the patterns that have been recorded for withdrawal from treatment? and what individual factors influenced withdrawal from BCG treatment?

\section{Methods}

A retrospective time interval analysis was undertaken.

\subsection{Population}

The study was undertaken in a cancer centre based in a large National Health Service Hospital Trust serving a large metropolitan area in Northern England. The area had traditionally been characterised by heavy industries such as coal mining and textiles, but, latterly as chemical manufacturing. One in six of the local population are aged 65 years or over ${ }^{43}$.

This population is diverse and undergoing change. Partly in consequence of easing of European borders, allowing easier movement of working age adults seeking employment. The ethnic make-up of the white population in this area has changed, growing from $3.3 \%$ in 2001 to $7.2 \%$ in 2011 . This is due to an influx of a largely Eastern European population e.g. Polish. The remainder of the population are of a black and ethnic minority population predominately of Indian sub-continent heritage. The district is the $67^{\text {th }}$ out of 326 districts, most deprived districts in England, with $12.5 \%$ living in areas rated in the $10 \%$ most deprived. Life expectancy of local males is 77 years and 81 years for females. Cancer incidence and mortality in this district is higher than other manufacturing towns in England ${ }^{43}$. 


\subsection{Sample}

Patients aged over 18 years with a histological diagnosis of NMIBC were included in this analysis. They had a grading of grade 3 bladder cancer with one, or a combination of, the following stages: Ta; T1; or carcinoma in situ (CIS). Commencing BCG treatment within the 12 months prior to the commencement of this study and had withdrawn from treatment. Patients who had progression or recurrence of bladder cancer and were not receiving BCG treatment were excluded.

A sample of 234 sets of patient case notes (1st January 2004 to 31st December 2011), fitted the inclusion criteria, which were included in this study. This was considered representative of the population ${ }^{44}$. The characteristics of the sample are described in table 2.

Ethical approval was obtained from local research ethics committee (12/YH/0481) and the university where study was conducted. The researchers were not involved in the administration of intravesical BCG treatment or in the management of any of the healthcare professionals (HCPs) within the units where treatment was given.

\section{Data Collection}

A data extraction tool was designed and pilot tested by the researcher. Only the researcher conducted the data extraction. The clinical data relating to BCG treatment received by patients gathered also illustrated the 'natural history' of BCG treatment and identified trends concerning symptomology e.g. timing of symptom occurrence 
and decisions recorded for treatment withdrawal. The tool was tested on a sample selection of case notes $(n=10)$ and adjustments made to refine the tool.

During the study, the NHS Trust moved towards being 'paper-light', hampering healthcare records collection of the data in three ways. Firstly, for those patients who still had paper notes, locating the notes and in many cases retrieving from storage took multiple requests and time delays. Secondly, paper notes already scanned into the electronic data management system posed different challenges. Such as delays caused by the time taken to scan documents and upload them and two the volume of screens of scanned documents per case note, as many as 500 , which needed to be reviewed to extract relevant data. Thirdly, some prescription cards were held by each unit and not with the case notes and these needed to be examined separately.

\section{Data Analysis}

Once extraction was completed, all data were transferred into IBM SPSS version 20 for Windows. Data were then analysed using the Kaplan-Meier method. This allows estimation of withdrawal over time, even when patients remain the study for different lengths of time ${ }^{45}$. Cox regression modelling was used to interrogate withdrawal data, allowing treatment effects to be isolated from influences of other variables ${ }^{45,46}$.

\section{Results}

There appears to be several significant factors or patterns that arise from the casenote analysis, which indicates a withdrawal rate of $90 \%$ and that the majority withdraw, 107 (46\%), from treatment within the first year. The most commonly recorded side effects involved a treatment related pain dimension e.g. pain, cystitis, sore genitalia. 
Urinary side effects such as frequency and urgency were also commonly reported. Age was also an important factor, as those who were 70 years or over were more likely to withdraw from treatment.

The findings are presented in five sections: study population and characteristics; patterns of withdrawal; factors influencing withdrawal; decisions for withdrawal; and Likelihood of withdrawal. The term 'time to event' for this study is defined as being the time taken to the event of interest namely withdrawal from BCG treatment.

\subsection{Study population and characteristics}

Most participants were aged over 70 years, 140 (61\%), and the majority were male, $188(80 \%)$. Only $23(10 \%)$ of the sample population completed the full three-year treatment regimen lower than the $16 \%$ identified in the South Western Oncology Group (SWOG) trial ${ }^{9}$.

Table. 2.

\subsection{Patterns of withdrawal}

The time to event analysis looked at protocol deviation by charting each instillation and the timing between instillations. Thereby, looking for patterns or areas of variability. These variations can be seen in Figures 1-7, which illustrate a number of curves. The significance of the divergent patterns is addressed with the log rank test, this showed that there was correlation with age and that the chance of an event occurring e.g. having a side effect, rises with age. The data also shows that those who 
experienced one or more side effects were more likely to withdraw from treatment early, $71(53 \%)$ withdrawing within 35 days of starting treatment.

Fig. 1 shows when each participant completed treatment. The largest withdrawal occurs prior to the one-year mark. From these data, $36(15 \%)$, of patients extended treatment beyond the three-year treatment protocol. This may be due to delays in the instillations, which then offset other instillations, being given later than planned, or the possibility that the patient had been lost to follow up and then continued when found.

Fig. 1.

Figure 2 shows that by concentrating the curve to 36 months, representing three years of treatment, it shows that patients are more likely to withdraw from treatment within the first 365 days (one year). On interrogation of those $107(46 \%)$ of patients that withdrew by 12 months, one year), of treatment a greater proportion, 39 (36\%), withdrew within the first 42 days (see Figure 3).

Fig. 2.

Fig. 3.

\subsection{Factors influencing withdrawal}

Fig. 4 shows comparison of time to withdrawal from treatment by age. Participants aged over 70 years have a lower time to event probability than those aged 69 years or younger. Log rank statistic $17.34(p=0.001)$. Age in this population was a significant 
factor in withdrawal from treatment. Likewise, those who experienced one or more side effect associated with BCG treatment (log rank statistic $7.27(p=0.007))$ were more likely to withdraw from treatment (See Figure 5).

Fig. 4.

Fig. 5.

As contact with a clinical nurse specialist (CNS) is one of the standards recommended in cancer standards ${ }^{47}$ compliance with this requirement was extracted from the case notes. Figure. 6 shows if a record of a patient receiving CNS contact information whereas Figure 7 illustrates receiving information about the treatment from a CNS. From these data it appears that receipt of contact details of a CNS (log rank statistic 4.46; $p=0.035$ ) or receiving information about the procedure and side effects (log rank statistic 23.052) $(p<0.001)$ was more likely to be associated with withdrawal from treatment.

Fig. 6.

Fig. 7.

\subsection{Decisions for withdrawal}

The reasons recording decisions to withdraw from treatment were categorised into five broad areas: Side effects, patient/carer, hospital related, disease related, or other reasons. The largest single grouping was treatment associated side effects (see Figures 8-10). The time to event analysis revealed, what appeared to be a natural age 
group split. Participants were grouped 69 years or younger and those aged 70 years or over. When categorised by age, there was little difference in the reasons given for withdrawing from treatment. Documented side effects appeared to be a major contributor to the decision to withdraw with two thirds, $156(67 \%)$ of participants, with at least one side effect recorded.

Fig. 8.

Fig. 9.

Fig. 10.

Side effects experienced are shown in Figs. 11-13. The majority of reported local symptoms were urinary including frequency of urination $(n=41,39 \%)$, haematuria $(n=$ $33,31 \%)$, cystitis ( $n=29,28 \%$ ) etc. Generalised pain which was not localised ( $n=22$, $31 \%$ ) was reported as being the most common systemic side effect. Unknown reactions (where a reaction was recorded, but no details given) $(n=18,39 \%)$ and difficulty in catheterisation were the most common other side effects reported.

Fig. 11.

Fig. 12.

Fig. 13. 


\subsection{Likelihood of withdrawal}

In the Cox regression modelling that was undertaken, all variables were considered for inclusion were screened. Those which did not appear important individually or comprised categories with frequencies too low to analyse were excluded. The remaining variables were then analysed in combination to identify any emerging patterns. This method assumes that covariates are multiplicatively related to the hazard e.g. experiencing a side effects raises the likelihood of withdrawal ${ }^{48}$. Variables included were those that: had a low p-value $(\leq 0.05)$ at 'screening stage' indicating the likelihood he variable occurring by chance was less than $5 \%$; were clinically important (side effects recorded as reason for patient withdrawal); or those selected through automated selection routine which the proportionality of the hazards assumption was validated. The variables that appear significant are presented in Table 3.

Table 3

\section{Discussion}

A major cause for early withdrawal was side effects, although age was associated with higher withdrawal rates. The reasons given for withdrawal from treatment were the same, or similar, in all age groups except for side effects. It was found that $31(40 \%)$ of participants aged 69 years or younger side effects were cited as a reason for withdrawing from treatment, a higher proportion than the 44 (33\%) of participants aged 70 years or older. These results are in contrast to Heiner and Terris's study, where the number of patients who experienced side effects aged 70 years or over were higher than in patients 69 years or younger respectively, $56 \%$ vs. $40 \%{ }^{49}$. Although reported as significant $(p<0.00001)$, the study sample was small, 58 participants, with only 22 
experiencing side effects suggesting it was underpowered. The number of participants who experienced side effects were greater 156 participants in this study; with 92 (59\%) aged over 70 years experiencing at least one side effect. An alternate explanation could relate the strains and/or doses of BCG administered. In the absence of consistent practice regarding optimum strain or dose ${ }^{30-32}$, this inconsistency may explain varying levels of withdrawal. Similarly, differences in number and severity of side effects experienced may strain or dose dependent. Within this analysis all patients received the same strain of $B C G$.

Some suggest that interstitial BCG treatment needs to be administered cautiously in patients 70 years or older and only after careful consideration due to poor reserves that these patients may have to cope with the treatment ${ }^{50}$. This is predicated on the basis that side effects from BCG treatment would not be as well tolerated in elderly patients and may become problematic in terms of adherence. This pattern was seen in this study population. Whether this was a consequence of poor toleration or the treatment burden was in excess of physical reserves and/or co-morbidity was not assessed.

The analysis supports the given view that side effects experienced affects attrition. Patients who are well prepared about what to expect, such as those involved in clinical trials, may be better prepared when encountering side effects; in effect they cope by normalising the abnormal. The results of this study suggest that those patients who are given more information, were more likely to withdraw. 
A surprising feature of this study and should be treated cautiously, was contact with a CNS may not contribute to keeping patients on treatment for longer. The reasons for this finding are unknown but warrants further investigation, particularly, as in other cancer site specific studies CNS input seems to improve outcomes ${ }^{51}$. However, this could be related to poor record keeping, in that those case records where details of the CNS were provided, patients were more likely to withdraw from treatment early, than those whose records showed they only received written information.

The time to event analysis of withdraw from treatment revealed a natural age group split with patients 69 years and under more likely to tolerate and continue to receive BCG for nine months longer than those aged 70 years and above. Further, $63 \%$ of the population aged above 70 years old in this study were more likely to withdraw reasons for attrition were similar. Not only was there a correlation between age and the chance of the event occurring, but the modelling highlighted that the percentage chance of the event occurring rises with age.

During data extraction three patient records documented the rationale for treatment cessation as 'advanced age'. This does question whether an adequate assessment was completed prior to treatment. The higher number of participants aged 70 years or greater in the study probably reflects the local population, with increasing life expectancy and effects of exposure to dye, printing, iron, industrial painting, gas and tar industries during employment only presenting long after exposure ${ }^{8}$. This generation may not have benefitted from the impact of health and safety legislation in the work place or recent anti-smoking campaigns ${ }^{52}$. 
There is clear evidence of side effects associated with BCG use 9,26,27. Reportedly between $20 \%$ and $80 \%$ of patients experience mild to severe local or systematic, side effects ${ }^{53-55}$. The reported studies do not detail the effect that side effects have on the patient.

This study discovered that $67 \%$ of patients who experienced one or more side effect, such as cystitis or incontinence, were more likely to withdraw early. The analysis showed that $55 \%$ of participants withdrew within the first year. Of these, $39 \%$ withdrew within 42 days of treatment commencing, hence failing to complete the induction phase of the treatment (the initial six instillations). Data regarding subsequent treatment(s) if any or long terms outcomes was not extracted and therefore any assumptions about whether patients were being put at risk of recurrence through early withdrawal are unknown. That said poor selection for BCG may have delayed alternative interventions.

Nearly half of the of participants (45\%) reported at least one local side effect e.g. urinary frequency; with $30 \%$ reporting at least one systemic side effect; and $20 \%$ reporting at least one other side effect or treatment related complication e.g. difficulty in catheterisation. The most common local side effect reported was cystitis and according to Lamm et al. experienced in around $80 \%$ receiving $B C G{ }^{53}$. In contrast, in this study, cystitis was recorded in only $28 \%$ of cases (Fig. 11). The most commonly recorded local side effect in was urinary frequency in $39 \%$ of cases. A possible reason for differences in symptom incidence may relate to how side effects were reported and/or recorded in case notes. Cystitis involves both frequency and pain, or a burning sensation, when urinating ${ }^{56}$. As the instillation of BCG is largely a nurse led service, 
in that the CNS counsels the patient, instils the BCG, records in the case notes and discharges the patient from the unit. They remain the main contact for the patient when they go home, therefore, this impacts onto any findings. The CNS may have recorded these side effects separately, or one in preference to both, or interpreted the symptoms and given a different descriptor thereby skewing the actual number of participants who did have the side effect of cystitis.

It is unclear in the literature when side effects occur. Some authors indicate that side effects can occur during the induction phase of the treatment, however they do not suggest that there is a cumulative effect from the BCG instillations when the symptoms appear during maintenance ${ }^{49,57-59}$. In this study there were $53 \%$ reports of side effects experienced within 35 days of starting treatment indeed for some these started within the first week of treatment commencing.

A limitation of all studies interrogating clinically available data, is the quality of the original record keeping and accuracy of data extraction. As this study used paperbased notes (patient records and prescription charts) this may have introduced greater levels of inaccuracy as clinician preference and style may influence what is recorded. Unlike electronic records which force data entry arguably increasing reliability ${ }^{60}$. Although some suggest the problem of data accuracy has more to do with why it is collected namely research versus clinical purposes. The introduction of electronic health records may have increased the tendency for bad data recording rather than greater accuracy ${ }^{61}$. 


\section{Conclusions}

From this retrospective time interval analysis of clinical data withdrawal rates from BCG treatment were higher than those published in the literature. The patterns that emerged associated with age and experience of side effects appeared to significantly affect the decision making regarding early withdrawal from treatment. The majority of attrition appears to occur within the first year of treatment, and indeed a sizable group prior to completing induction. Possibly the most surprising finding was that clinical nurse contact and information provision seemed to exacerbate early withdrawal. This may be an anomaly associated with a real-world nurse led service design. What is clear is that further research is required to fully understand these results, but they contribute real world insight into the experience of a 'gold standard' treatment. 


\section{References}

1. Cancer research UK. Bladder cancer statistics | Cancer Research UK.

2. Pelucchi C, Bosetti C, Negri E, Malvezzi M, La Vecchia C. Mechanisms of disease: The epidemiology of bladder cancer. Nat Clin Pract Urol. $2006 ; 3(6): 327-340$.

3. Office for National Statistics. 170 years of industrial change across England and Wales. http://www.ons.gov.uk/ons/rel/census/2011-census-analysis/170years-of-industry/170-years-of-industrial-changeponent.html. Published 2013. Accessed August 30, 2014.

4. Burger M, Catto JWF, Dalbagni G, et al. Epidemiology and risk factors of urothelial bladder cancer. Eur Urol. 2013;63(2):234-241.

doi:10.1016/j.eururo.2012.07.033

5. Chavan S, Bray F, Lortet-Tieulent J, Goodman M, Jemal A. International variations in bladder cancer incidence and mortality. Eur Urol. 2014;66(1):5973. doi:10.1016/j.eururo.2013.10.001

6. Freedman ND. Association Between Smoking and Risk of Bladder Cancer Among Men and Women. JAMA. 2011;306(7):737. doi:10.1001/jama.2011.1142

7. van Osch FH, Jochems SH, van Schooten F-J, Bryan RT, Zeegers MP. Quantified relations between exposure to tobacco smoking and bladder cancer risk: a meta-analysis of 89 observational studies. Int J Epidemiol. 2016;45(3):857-870. doi:10.1093/ije/dyw044

8. Babjuk M, Burger M, Compérat E, et al. Non-muscle-invasive Bladder Cancer. http://uroweb.org/guideline/non-muscle-invasive-bladder-cancer/. Published 2017. Accessed April 9, 2018. 
9. Lamm D, Blumenstein B, Crissman J, et al. Maintenance bacillus CalmetteGuerin immunotherapy for recurrent TA, T1 and carcinoma in situ transitional cell carcinoma of the bladder: A randomized Southwest Oncology Group Study. J Urol. 2000;163(4):1124-1129.

10. Crispen R. History of BCG and its substrains. Prog Clin Biol Res. 1989;310:3550.

11. Huang T. Management of complications of bacillus Calmette-Guerin immunotherapy in the treatment of bladder cancer. Ann Pharmacother. $2000 ; 34(4): 529-532$

12. Pearl R. Cancer and tuberculosis. Am J Hyg. 1929;9(1):97-159.

13. Mathe G, Amiel J, Schwarzenberg L, et al. Active immunotherapy for acute lymphoblastic leukaemia. Lancet. 1969;1(7597):697-699.

14. Morton D, Eilber F, Malmgren R, Wood W. Immunological factors which influence response to immunotherapy in malignant melanoma. Surgery. 1970;68(1):158-163.

15. Zbar B, Bernstein I, Bartlett G, Hanna M, Rapp H. Immunotherapy of cancer: Regression of intradermal tumors and prevention of growth of lymph node metastases after intralesional injection of living mycobacterium bovis. J Natl Cancer Inst. 1972;49(1):119-130.

16. Coe J, Feldman J. Extracutaneous delayed hypersensitivity, particularly in the guinea-pig bladder. Immunology. 1966;10(2):127-136.

17. Morales A, Eidinger D, Bruce A. Intracavitary Bacillus Calmette-Guerin in the treatment of superficial bladder tumors. J Urol. 1976;116(2):180-183.

18. Lamm D. Bacillus Calmette-Guerin immunotherapy for bladder cancer. J Urol. 1985;134(1):40-47. 
19. Mori K, Lamm D, Crawford E. A trial of bacillus Calmette-Guérin versus adriamycin in superficial bladder cancer: A south-west oncology group study. Urol Int. 1986;41(4):254-259.

20. Herr H, Pinsky C, Whitmore W, Oettgen H, Melamed M. Effect of intravesical bacillus Calmette-Guerin (BCG) on carcinomain situ of the bladder. Cancer. 1983;51(7):1323-1326.

21. Herr H, Pinsky C, Whitmore W, Sogani P, Oettgen H, Melamed M. Experience with intravesical bacillus Calmette-Guèrin therapy of superficial bladder tumors. Urology. 1985;25(2):119-123.

22. Melekos M, Chionis H, Pantazakos A, Fokaefs E, Paranychianakis G, Dauaher H. Intravesical bacillus Calmette-Guerin immunoprophylaxis of superficial bladder cancer: Results of a controlled prospective trial with modified treatment schedule. J Urol. 1993;149(4):744-748.

23. Krege S, Giani G, Meyer R, Otto T, Rübben H. A randomized multicenter trial of adjuvant therapy in superficial bladder cancer: Transurethral resection only versus transurethral resection plus mitomycin $\mathrm{C}$ versus transurethral resection plus bacillus Calmette-Guerin. Participating Clinics. J Urol. 1996;156(3):962966.

24. Lamm D. Long-term results of intravesical therapy for superficial bladder cancer. Urol Clin North Am. 1992;19(3):573-580.

25. Bohle A, Jocham D, Bock P. Intravesical bacillus Calmette-Guerin versus mitomycin $\mathrm{C}$ for superficial bladder cancer: A formal meta-analysis of comparative studies on recurrence and toxicity. J Urol. 2003;169(1):90-95.

26. Hinotsu S, Akaza H, Naito S, et al. Maintenance therapy with bacillus calmetteguerin connaught strain clearly prolongs recurrance-free survival following 
transurethral resection of bladder tumour for non-muscle-invasive bladder cancer. BJU Int. 2010;108(2):187-195.

27. Sylvester R, Brausi M, Kirkels W, et al. Long-term efficacy results of EORTC genito-urinary group randomized phase 3 study 30911 comparing intravesical instillations of epirubicin, bacillus Calmette-Guérin, and bacillus CalmetteGuérin plus isoniazid in patients with intermediate- and high-risk. Eur Urol. 2010;57(5):766-773.

28. Sylvester R, van der Meijden A, Lamm D. Intravesical bacillus Calmette-Guerin reduces the risk of progression in patients with superficial bladder cancer: a meta-analysis of the published results of randomized clinical trials. J Urol. 2002;168:1964-1970.

29. Shelley M, Kynaston $\mathrm{H}$, Court J, et al. A systematic review of intravesical bacillus Calmette-Guérin plus transurethral resection vs transurethral resection alone in Ta and T1 bladder cancer. BJU Int. 2001;88(3):209-216.

30. Shelley M, Court J, Kynaston H, Wilt T, Fish R, Mason M. Intravesical Bacillus Calmette-Guérin in Ta and T1 bladder cancer (Review). Cochrane Libr. 2010;(3).

31. Fonseca F, Bachega W, Zequi S, et al. Treatment of patients with superficial bladder cancer stratified by risk groups treated with lyophilized Moreau-Rio de Janeiro BCG strain. Int Brazilian J Urol. 2002;28(5):426-435.

32. Hudson M, Ratliff T, Gillen D, Haaff E, Dresner S, Catalona W. Single course versus maintenance bacillus Calmette-Guerin therapy for superficial bladder tumors: a prospective, randomized trial. J Urol. 1987;162(2):339-342.

33. Kamat AM, Flaig TW, Grossman HB, et al. Expert consensus document: Consensus statement on best practice management regarding the use of 
intravesical immunotherapy with BCG for bladder cancer. Nat Rev Urol. $2015 ; 12(4): 1-11$

34. Rentsch C, Birkhäuser F, Biot C, et al. Bacillus Calmette-Guérin strain differences have an impact on clinical outcome in bladder cancer immunotherapy. Eur Urol. 2014;66(4):677-688.

35. Oddens J, Brausi M, Sylvester R, et al. Side effects of bacillus calmette-guérin $(B C G)$ in the treatment of intermediate- and high-risk Ta, T1 papillary carcinoma of the bladder: Results of the EORTC genito-urinary cancers group randomised phase 3 study comparing one-third dose with full dose an. Eur Urol. 2014;65(1):69-76. http://www.ncbi.nlm.nih.gov/pubmed/23141049. Accessed October 24, 2016.

36. Hall M, Chang S, Dalbagni G, et al. Guideline for the management of nonmuscle invasive bladder cancer (stages Ta, T1, and Tis): 2007 update. J Urol. 2007;178(6):2314-2330.

37. Babjuk M, Böhle A, Burger M, et al. Guidelines on Non-Muscle-Invasive Bladder Cancer (Ta, T1 and CIS). European Association of Urology; 2014.

38. National Comprehensive Cancer Network. Clinical practice guidelines in oncology: bladder cancer including upper tract tumors and urothelial carcinoma of the prostate. 2012.

39. Paul A, Carey B, Cross B, Rock C, Singh P. Guidelines for the investigation and treatment of bladder, renal and prostate cancers. Yorkshire Cancer Network. http://www.yorkshire-cancer-net.org.uk/html/downloads/ycn-urologybladder-renal-prostate-guidelines-sept2012-v2.0.pdf. Published 2012. Accessed October 16, 2012.

40. Zlotta A, Van Vooren J, Huygen K, et al. What Is the Optimal Regimen for 
BCG Intravesical Therapy? Are Six Weekly Instillations Necessary? Vol 37.; 2000.

41. Kitamura H, Tsukamoto $\mathrm{T}$. Immunotherapy for urothelial carcinoma: Current status and perspectives. Cancers (Basel). 2011;3(3):3055-3072.

42. Lockyer C, Gillatt D. BCG immunotherapy for superficial bladder cancer. J R Soc Med. 2001;94(3):119-123.

43. Wakefield Together Partnership. Our Wakefield: The State of District Report Winter 2012 Update. Wakefield: Wakefield Together Partnership; 2012.

44. Patel M, Doku V, Tennakoon L. Challenges in recruitment of research participants. Adv Psychiatr Treat. 2003;9(3):229-238.

45. Buchan I. Statistical Help. Statsdirect. http://www.statsdirect.com/help/Default.htm\#contents.htm?TocPath= 1. Published 2016. Accessed July 17, 2016.

46. Walters S. What Is a Cox Model? 2nd ed. Hayward Medical Communications; 2009.

47. National Institute for Clinical Excellence. Guidance on Cancer Services: Improving Outcomes in Urological Cancers - The Manual. London: National Instiute for Clinical Excellance; 2002.

48. Breslow N. Analysis of Survival Data under the Proportional Hazards Model. Int Stat Rev / Rev Int Stat. 1975;43(1):45-57.

49. Heiner J, Terris M. Effect of advanced age on the development of complications from intravesical bacillus Calmette-Guérin therapy. Urol Oncol. 2008;26(2):137-140.

50. Shariat S, Milowsky M, Droller M. Bladder cancer in the elderly. Urol Oncol. 2009;27(6):653-667. 
51. Tod AM, Redman J, McDonnell A, Borthwick D, White J. Lung cancer treatment rates and the role of the lung cancer nurse specialist: a qualitative study. BMJ Open. 2015;5(12):e008587. doi:10.1136/bmjopen-2015-008587

52. ASH: Action on Smoking and Health. http://www.ash.org.uk/. Published 2016. Accessed July 17, 2016.

53. Lamm D, Persad R, Colombel M, Brausi M. Maintenance bacillus CalmetteGuérin: The standard of care for the prophylaxis and management of intermediate- and high-risk non-muscle-invasive bladder cancer. Eur Urol Suppl. 2010;9(9):715-734.

54. van der Meijden A, Sylvester R, Oosterlinck W, Hoeltl W, Bono A. Maintenance bacillus Calmette-Guerin for Ta T1 bladder tumors is not associated with increased toxicity: Results from a european organisation for research and treatment of cancer genito-urinary group phase III trial. Eur Urol. 2003;44(4):429-434.

55. Bohle A, Balck F, Wietersheim J, Jocham D. The quality of life during intravesical bacillus Calmette-Guerin therapy. J Urol. 1996;155:1221-1226.

56. Brusch J, Bavaro M, Cunha B, Tessler JM. Urinary Tract Infection (UTI) and Cystitis (Bladder Infection) in Females: Practice Essentials, Background, Pathophysiology. Medscape. https://emedicine.medscape.com/article/233101overview\#showall. Published 2017. Accessed April 23, 2018.

57. Orihuela E, Herr H, Pinsky C, Whitmore W. Toxicity of intravesical BCG and its management in patients with superficial bladder tumors. Cancer. 1987;60(3):326-333.

58. Berry D, Blumenstein B, Magyary D, Lamm D, Crawford E. Local toxicity patterns associated with intravesical bacillus Calmette-Guérin: A Southwest 
Oncology Group Study. Int J Urol. 1996;3(2):98-100.

59. Mack D, Frick J. Quality of life in patients undergoing bacille Calmette-Guérin therapy for superficial bladder cancer. Br J Urol. 1996;78(3):369-371.

60. Kuhn T, Basch P, Barr M, et al. Clinical documentation in the 21st century: Executive summary of a policy position paper from the American College of Physicians. Ann Intern Med. 2015;162(4):301-303. doi:10.7326/M14-2128

61. Weiskopf N, Weng C. Methods and dimensions of electronic health record data quality assessment: Enabling reuse for clinical research. J Am Med Informatics Assoc. 2013;20(1):144-151. doi:10.1136/amiajnl-2011-000681 
Fig. 1: Early withdrawal or course completion overall view

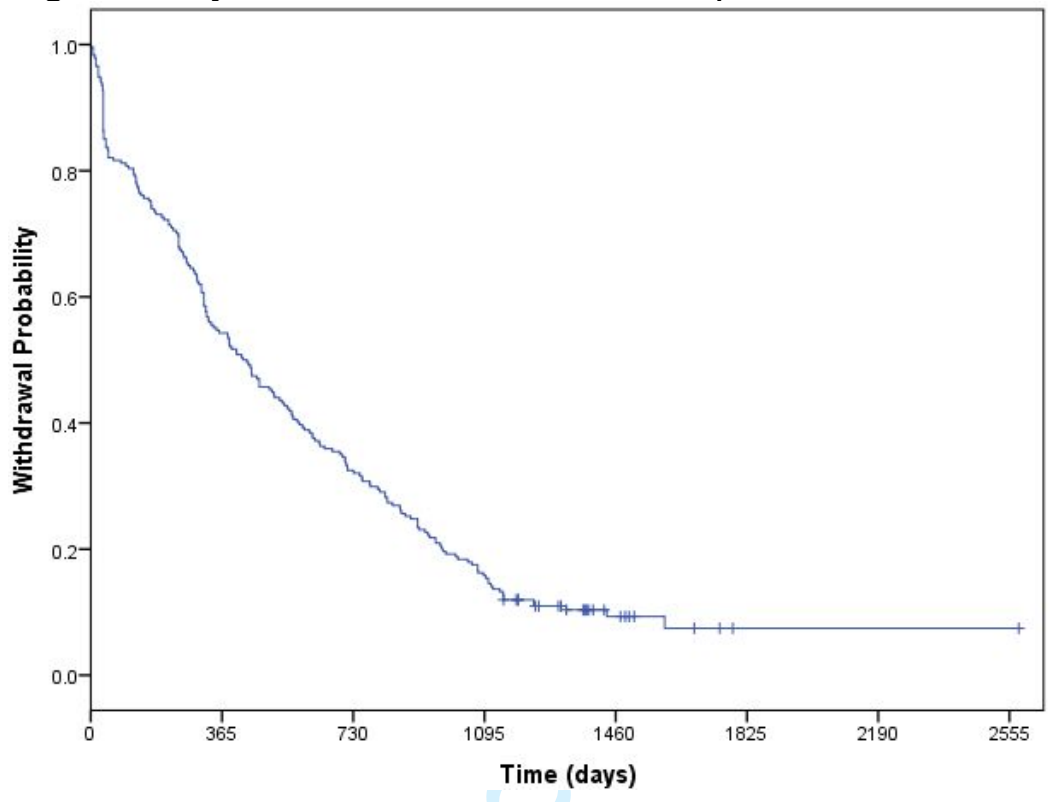

Fig. 2: Early withdrawal or completed 36 months (three years) of treatment

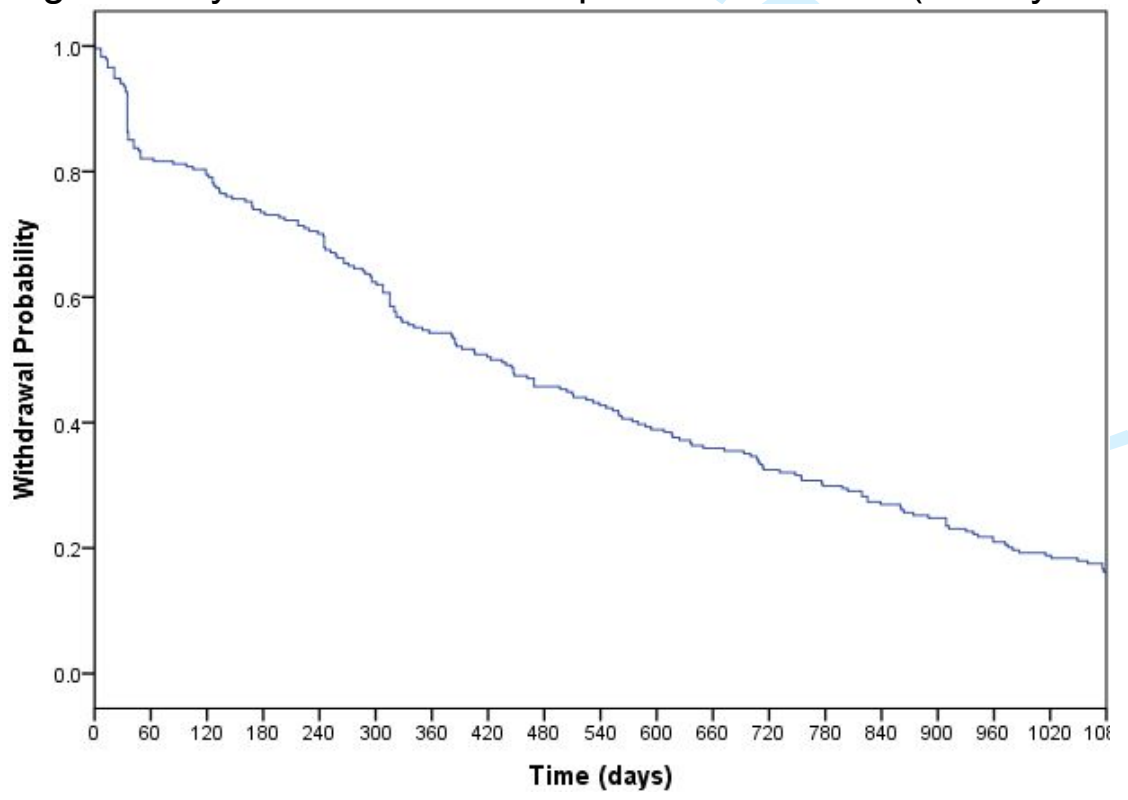


Fig. 3: Early withdrawal or completed 12 months (one year) of treatment



Fig. 4: Treatment withdrawal by age group




Fig. 5: Early withdrawal through side effects

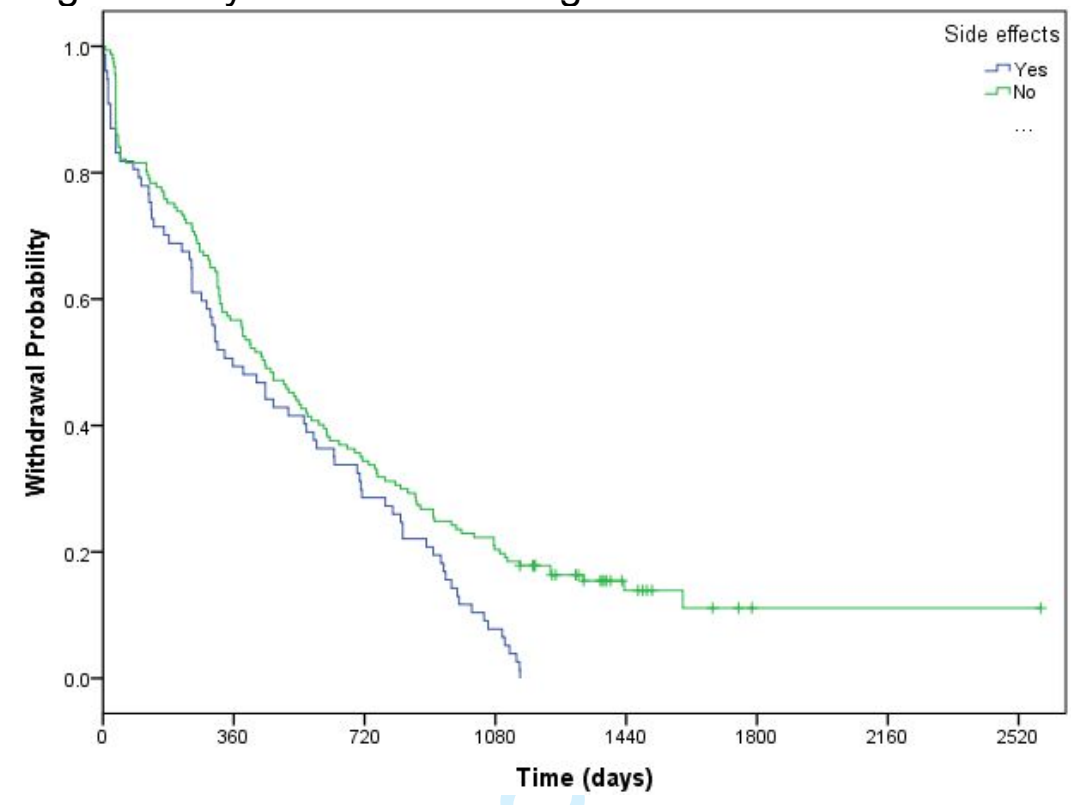

Fig. 6: CNS contact details given to a patient

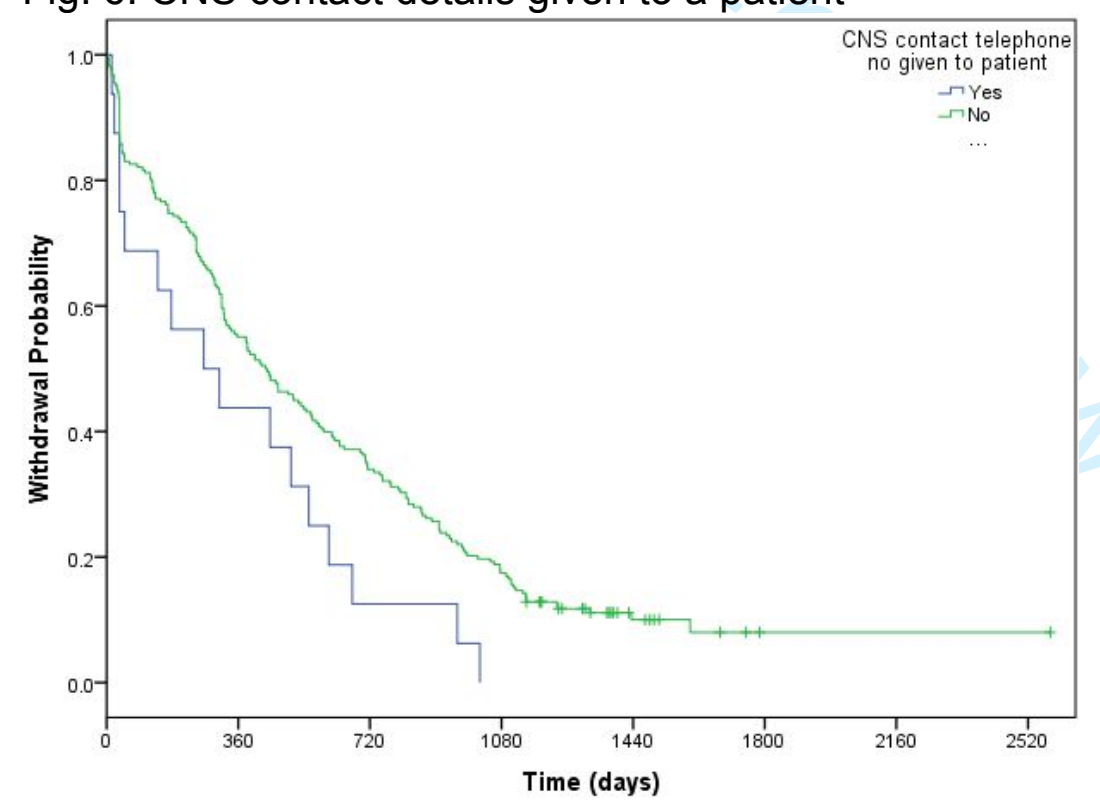


Fig. 7: Written information given to a patient



Fig. 8: Reasons given for withdrawal

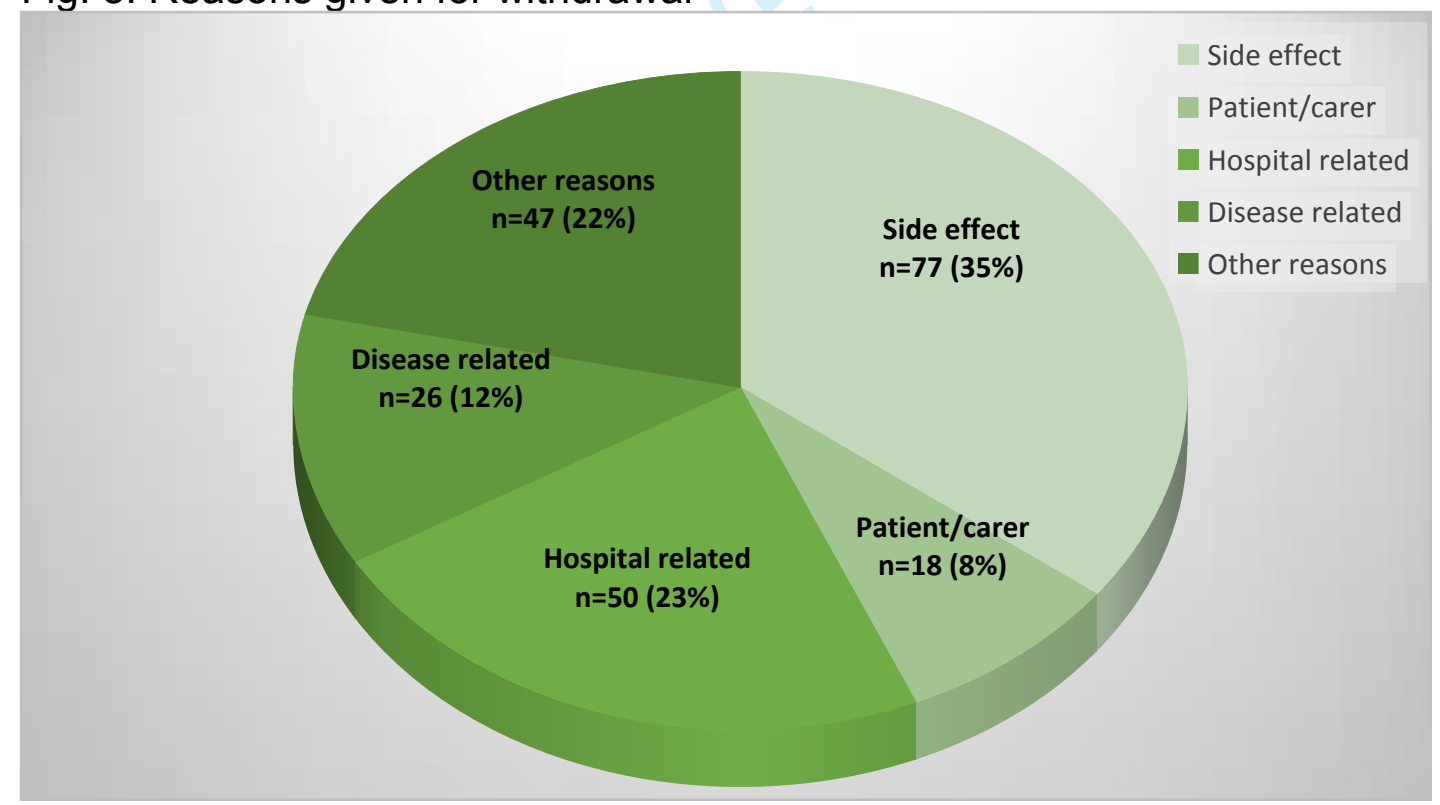


Fig. 9: Comparison of withdrawal reasons by age

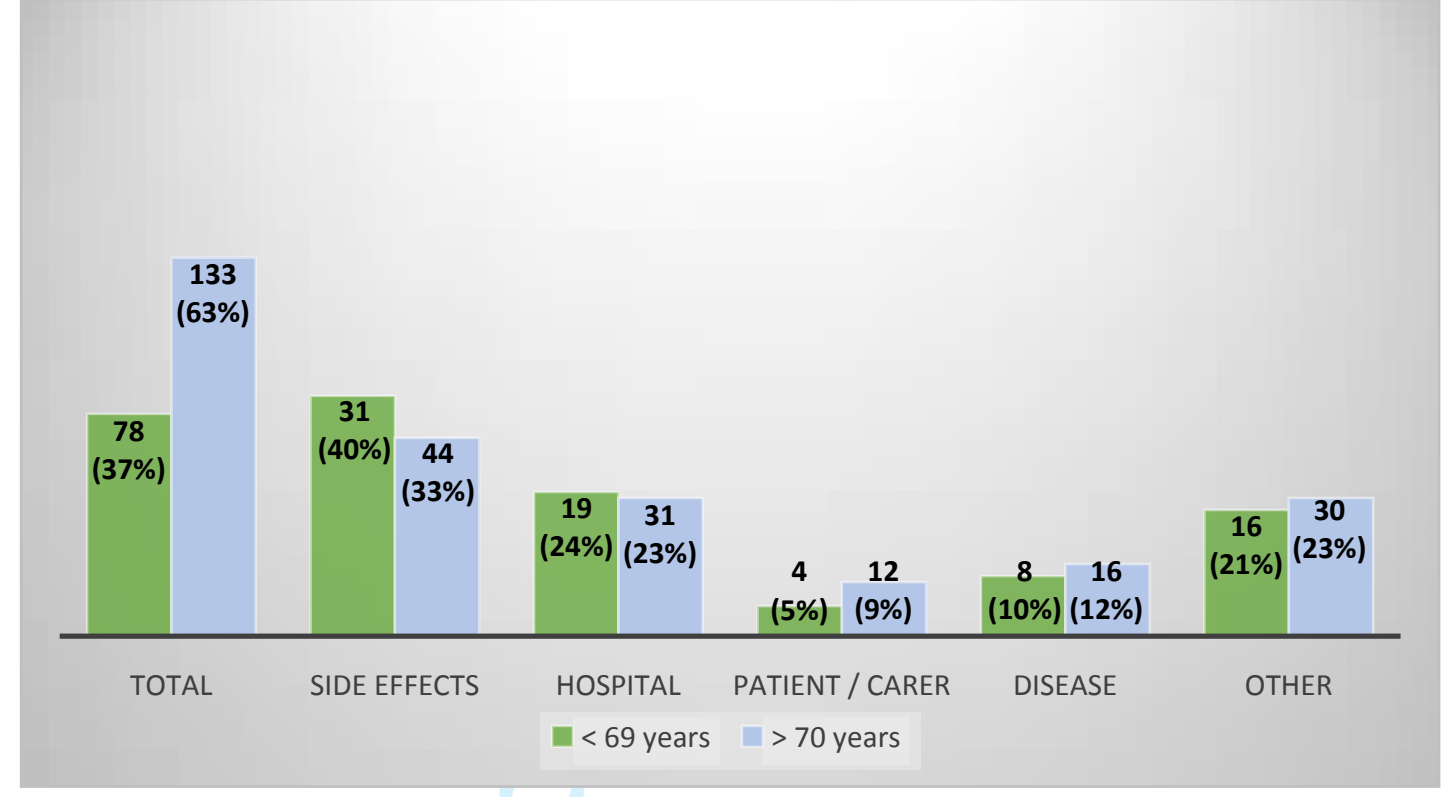

Fig. 10: Recorded number of side effects from case notes

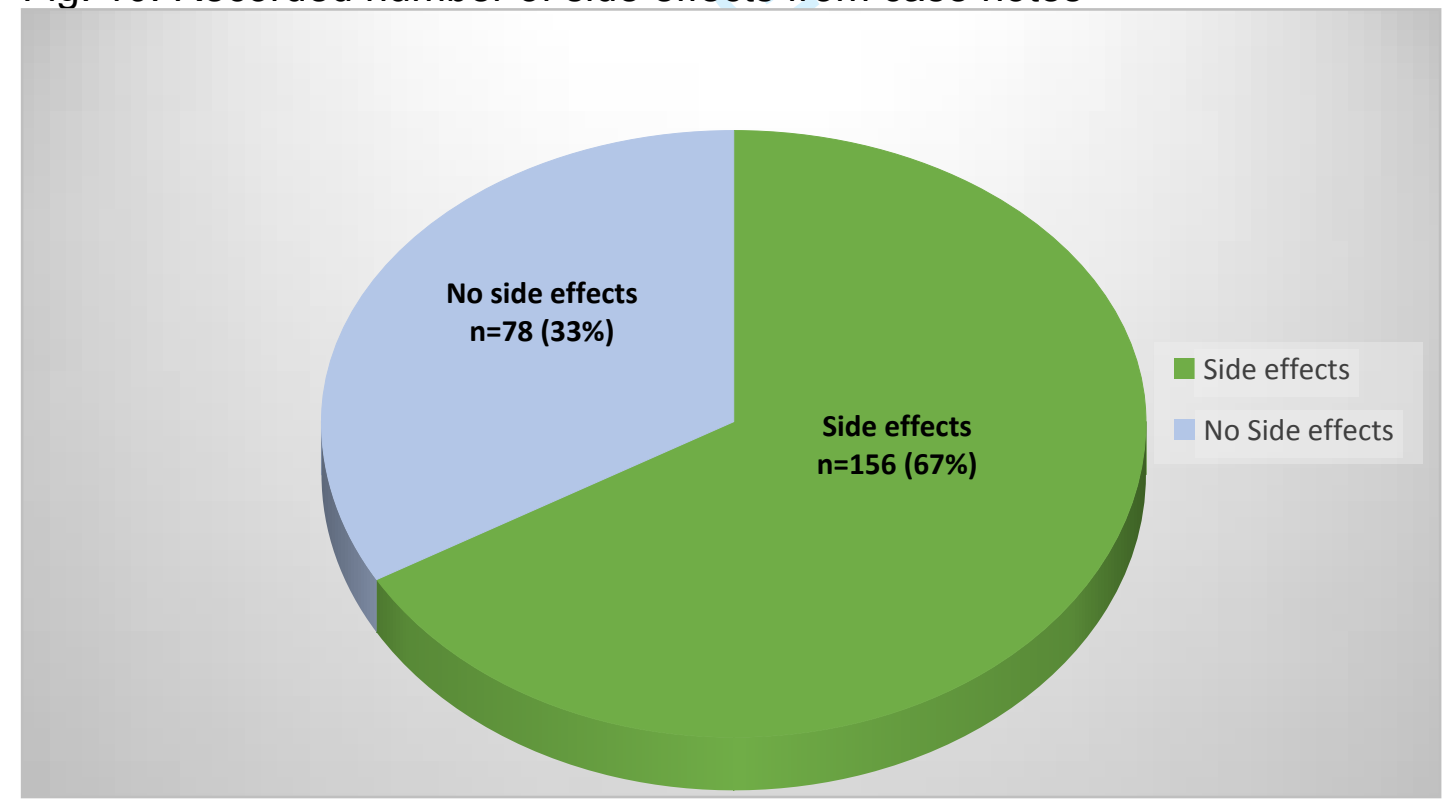


Fig. 11: Reported local side effects

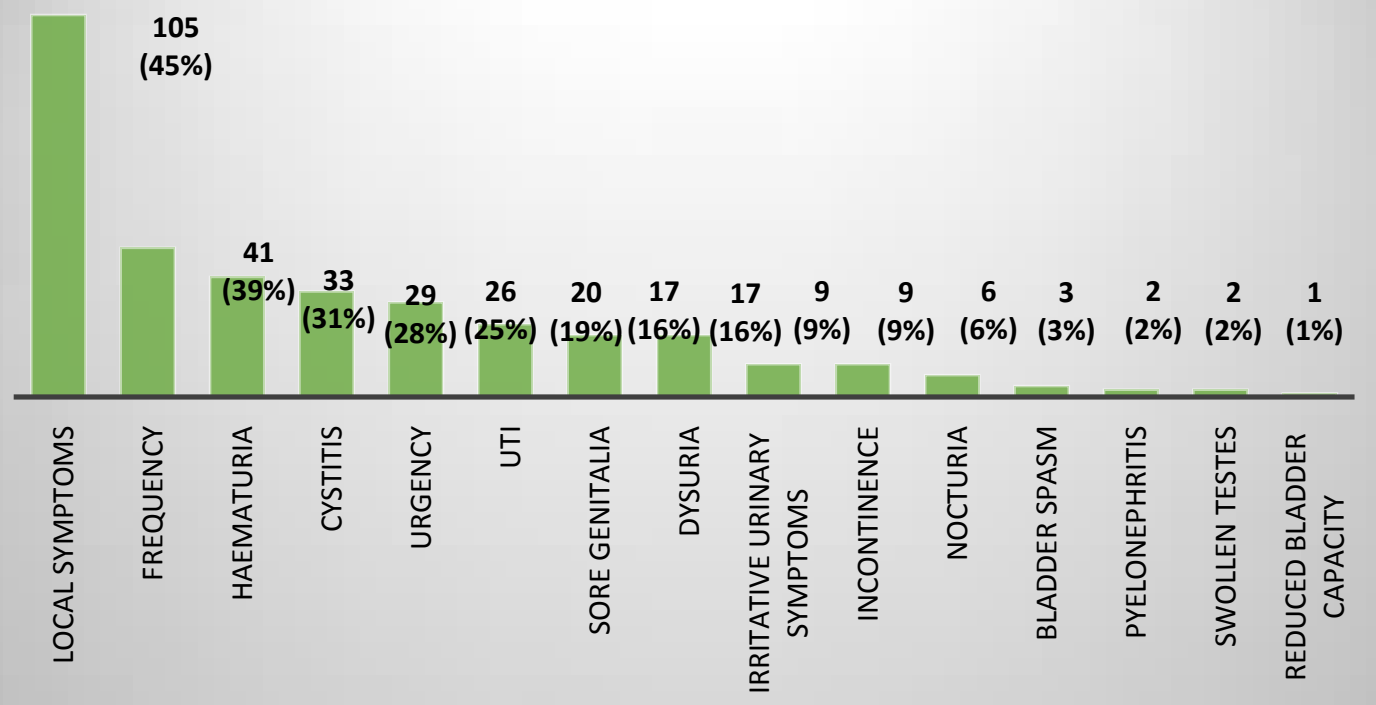

Fig. 12: Reported systemic side effects

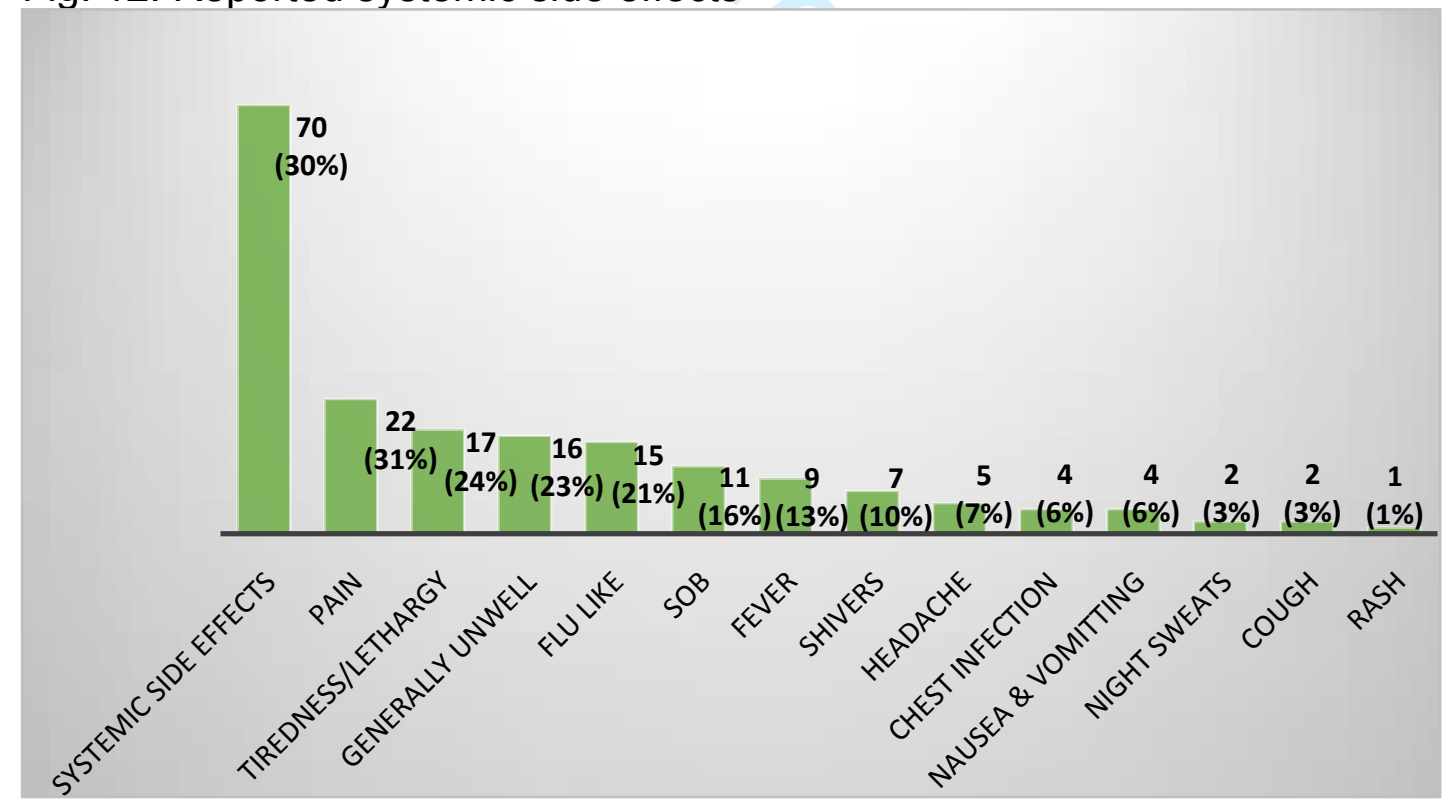


Fig. 13: Reported 'other' side effects

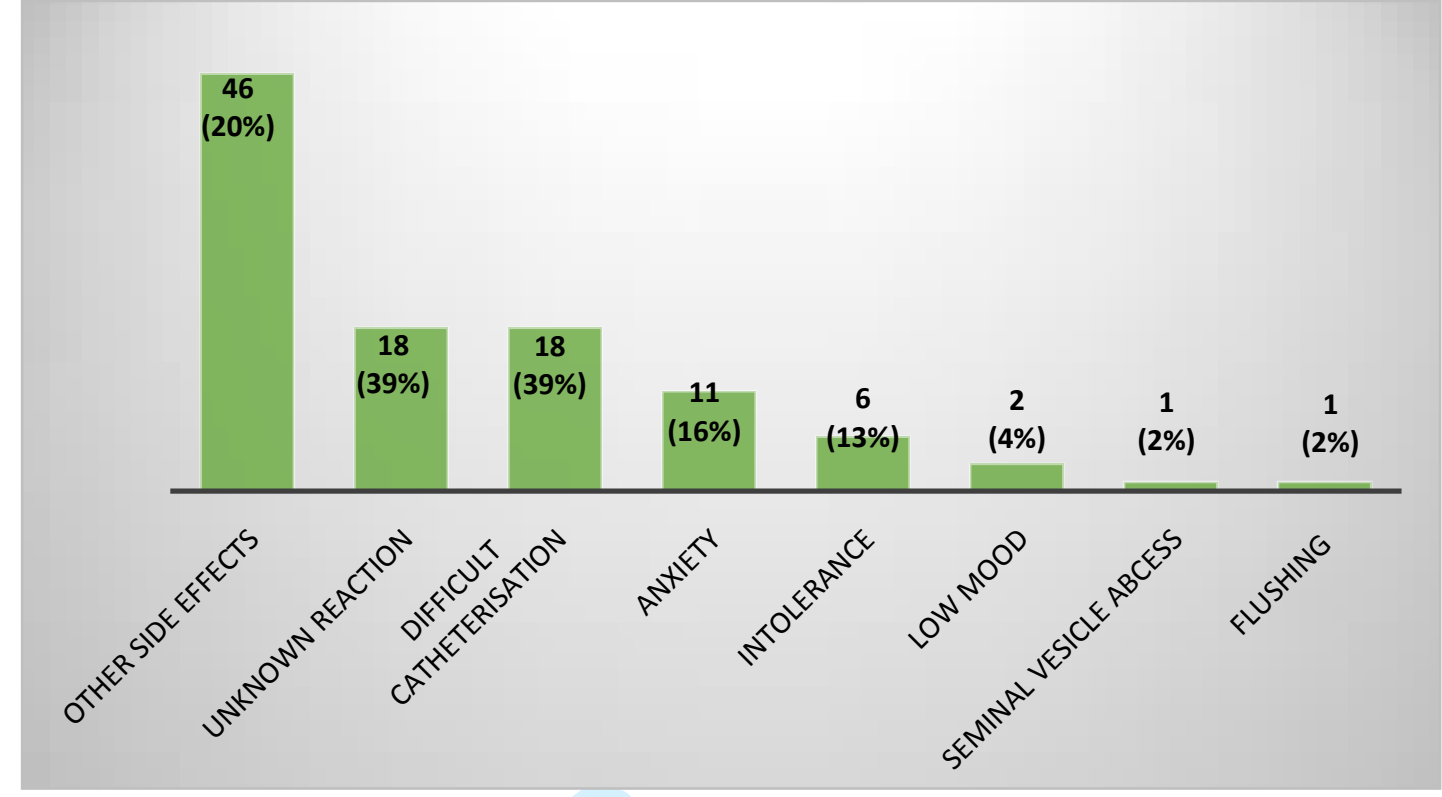


Table 1: Studies showing BCG dose, strain and treatment regime

\begin{tabular}{|c|c|c|c|c|}
\hline Study & Dose / Strain & Induction Regime & Maintenance Regime & $\begin{array}{l}\text { Percutaneous } \\
\text { BCG }\end{array}$ \\
\hline Morales et al. (1976) & 120mg / Armand Frappier & Weekly for 6 weeks & No & Yes \\
\hline Herr et al. (1983) & 120mg / Armand Frappier & Weekly for 6 weeks & No & Yes \\
\hline Badalament et al. (1987) & 120mg / Armand Frappier & Weekly for 6 weeks & Monthly for 2 years & No \\
\hline Hudson et al. (1987) & 120mg / Pasteur & No & $\begin{array}{l}1 \text { instillation every } 3 \\
\text { months for } 2 \text { years }\end{array}$ & No \\
\hline Agrawal et al. (2007) & 40,80,120mg / Modified Danish 1331 & Weekly for 6 weeks & Monthly for 1 year & No \\
\hline Ali-el-dein et al. (1999) & 150mg / Strain not given & Weekly for 6 weeks & Monthly for 10 months & No \\
\hline Andius \& Holmang (2004) & $\begin{array}{l}\text { Dose not stated / Modified Danish } \\
1331 \text { \& TICE }\end{array}$ & Weekly for 6 weeks & Monthly for 2 years & No \\
\hline Orihuela et al. (1987) & 120mg / Pasteur & Weekly for 6 weeks & No & Yes \\
\hline Lamm et al. (1995) & $50 \mathrm{mg} / \mathrm{TICE}$ & Weekly for 6 weeks & Monthly for 1 year & No \\
\hline Bohle et al. (1996) & 150mg / Connaught & Weekly for 6 weeks & No & No \\
\hline Krege et al. (1996) & 120mg / Connaught & Weekly for 6 weeks & Monthly for 4 months & No \\
\hline Taniguchi et al. (1999) & 80mg / Tokyo 172 & Weekly for 6 weeks & No & No \\
\hline Witjes et al. (1996) & $5 \times 10^{8} /$ TICE \& RIVM & Weekly for 6 weeks & No & No \\
\hline Witjes et al. (1998) & 40mg of Mitomycin C then BCG & Weekly for 6 weeks & No & No \\
\hline Lamm et al. (2000) & 81mg / Connaught & Weekly for 6 weeks & $\begin{array}{l}\text { Weekly for } 3 \text { weeks at } \\
\text { months } 3,6,12,18,24, \\
30 \text { and } 36\end{array}$ & Yes \\
\hline Saint et al. (2001) & 81mg / Connaught & Weekly for 6 weeks & $\begin{array}{l}\text { Weekly for } 3 \text { weeks at } \\
\text { months } 3,6,12,18,24 \\
30 \text { and } 36\end{array}$ & No \\
\hline van der Meijden et al. (2001) & $5 \times 10^{8} /$ TICE & Weekly for 6 weeks & $\begin{array}{l}\text { Weekly for } 3 \text { weeks at } \\
\text { months } 3,6,12,18,24, \\
30 \text { and } 36\end{array}$ & No \\
\hline
\end{tabular}




\begin{tabular}{|c|c|c|c|c|}
\hline Fonseca et al. (2002) & 40mg / Moreau-Rio de Janeiro & $\begin{array}{l}6 \text { instillations }- \text { not } \\
\text { clear over what time } \\
\text { period }\end{array}$ & $\begin{array}{l}6 \text { instillations each } 15 \\
\text { days }\end{array}$ & No \\
\hline van der Meijden et al. (2003) & $5 \times 10^{8} / \mathrm{TICE}$ & Weekly for 6 weeks & $\begin{array}{l}\text { Weekly for } 3 \text { weeks at } \\
\text { months } 3,6,12,18,24 \text {, } \\
30 \text { and } 36\end{array}$ & No \\
\hline De Reijke et al. (2005) & $81 \mathrm{mg} /$ Connaught & Weekly for 6 weeks & $\begin{array}{l}\text { Weekly for } 3 \text { weeks at } \\
\text { months } 3,6,12,18,24 \\
30 \text { and } 36\end{array}$ & No \\
\hline Gunlusoy et al. (2005) & 120mg / Pasteur & Weekly for 6 weeks & No & No \\
\hline Decobert et al. (2008) & $120 \mathrm{mg} /$ Pacis Shire & Weekly for 6 weeks & $\begin{array}{l}\text { Weekly for } 3 \text { weeks at } \\
\text { months } 3,6,12,18,24, \\
30 \text { and } 36\end{array}$ & No \\
\hline Jarvinen et al. (2009) & 75mg / Pasteur & Weekly for 5 weeks & Monthly for 2 years & No \\
\hline Duchek et al. (2010) & Dose not stated / TICE & Weekly for 6 weeks & $\begin{array}{l}\text { Weekly for } 3 \text { weeks at } \\
\text { months } 3,6,12,18,24 \\
30 \text { and } 36\end{array}$ & No \\
\hline Hinotsu et al. (2010) & $81 \mathrm{mg} /$ Connaught & Weekly for 6 weeks & $\begin{array}{l}\text { Weekly for } 3 \text { weeks at } \\
\text { months } 3,6,12 \text { and } 18\end{array}$ & No \\
\hline Sylvester et al. (2010) & $5 \times 10^{8} / \mathrm{TICE}$ & Weekly for 6 weeks & $\begin{array}{l}\text { Weekly for } 3 \text { weeks at } \\
\text { months } 3,6,12,18,24 \\
30 \text { and } 36\end{array}$ & No \\
\hline Oddens et al. (2014) & $5 \times 10^{8} /$ TICE & Weekly for 6 weeks & $\begin{array}{l}\text { Weekly for } 3 \text { weeks at } \\
\text { months } 3,6,12,18,24 \\
30 \text { and } 36 \text {; or }\end{array}$ & No \\
\hline
\end{tabular}




\begin{tabular}{|l|l|l|l|} 
& & $\begin{array}{l}\text { Weekly for } 3 \text { weeks at } \\
\text { months 3, 6 and 12 }\end{array}$ & \\
\hline Rentsch et al. (2014) & $\begin{array}{l}\text { 6.6-19.2 108 CFU / Connaught 2-8 } \\
108 \text { CFU / Tice }\end{array}$ & Weekly for 6 weeks & No \\
\hline
\end{tabular}


Table 2: The age distribution and gender of the population

\begin{tabular}{|lcc|}
\hline Characteristic & $\mathbf{n}$ & $\%$ \\
\hline Age (years) & & \\
$<59$ & 28 & $(12)$ \\
$60-69$ & 66 & $(28)$ \\
$70-79$ & 111 & $(48)$ \\
$>80$ & 29 & $(13)$ \\
Mean age & 71 & \\
Standard deviation & 8.54 & \\
\hline Gender & & \\
Male & 188 & $(80)$ \\
Female & 46 & $(20)$ \\
\hline Course Complete & & \\
Yes & 23 & $(10)$ \\
No & 211 & $(90)$ \\
\hline
\end{tabular}

Table 3: Cox regression model parameters

\begin{tabular}{|c|c|c|c|c|}
\hline Variable & $\begin{array}{c}\mathrm{p}- \\
\text { value }\end{array}$ & $\begin{array}{c}\text { Hazard } \\
\text { Ratio (HR) }\end{array}$ & \multicolumn{2}{|c|}{$\begin{array}{c}95.0 \% \mathrm{Cl} \text { for } \\
\text { HR }\end{array}$} \\
\hline \multicolumn{5}{|l|}{ Age } \\
\hline$>80$ (reference) & & & & \\
\hline$<59$ & 0.007 & 0.427 & 0.231 & 0.789 \\
\hline $60-69$ & 0.018 & 0.558 & 0.345 & 0.903 \\
\hline 70-79 & 0.241 & 0.765 & 0.490 & 1.197 \\
\hline \multicolumn{5}{|l|}{ Patients withdrawn due to: } \\
\hline \multicolumn{5}{|l|}{$\begin{array}{l}\text { No side effects or side effects } \\
\text { (reference) }\end{array}$} \\
\hline $\begin{array}{l}\text { Side effects or side effects } \\
\text { No patient or carer decisions (reference) }\end{array}$ & $<0.001$ & 5.443 & 3.481 & 8.510 \\
\hline $\begin{array}{l}\text { Patient or carer decisions } \\
\text { No hospital events (reference) }\end{array}$ & 0.002 & 2.379 & 1.368 & 4.134 \\
\hline $\begin{array}{l}\text { Hospital events } \\
\text { No miscellaneous reasons (reference) }\end{array}$ & $<0.001$ & 2.898 & 1.736 & 4.837 \\
\hline Miscellaneous reasons & $<0.001$ & 7.057 & 4.308 & $\begin{array}{c}11.56 \\
1\end{array}$ \\
\hline \multicolumn{5}{|l|}{ Patients who received: } \\
\hline $\begin{array}{l}\text { No information (reference) } \\
\text { Information }\end{array}$ & $<0.001$ & 1.857 & 1.322 & 2.610 \\
\hline \multicolumn{5}{|l|}{ Patients who experienced: } \\
\hline $\begin{array}{l}\text { No local side effects (reference) } \\
\text { Local side effects }\end{array}$ & 0.026 & 0.695 & 0.505 & 0.958 \\
\hline
\end{tabular}

